\section{CORK MEDICAL PROTECTIFE ASSOCIATION AND THE BILL.}

To the Right Honouralle and Honouratte the Lords Spiritual and Temporal in Purlicment assembled.

The petition of the Committee of the County and City of Cork Medical Protective Association, humbly sheweth,-

That the experience of the last twelve years has convinced your petitioners that the effeciency and usefulness of the General Iledical Counenl of Great Britain must remain extremely imperfect until considerable modifications in its constitution and working are efiected; and your petitioners therefore regret that that body has been al

purposes of the Medical Act, 1870 .
That the modifications which appear to your petitioners essential to the sucessful working of the measure wow before your honourable House are1. A reduction in the number of its members from its present cumbersom dimensions to one better calculated to accomplish practical results.

2. A more equable representation of the rarious bodies interested than at present exists. The representation might include the Unirersities, the other Licensing Bodies, and the General Body of the Afedical Profession of the
Cuited Kingdom; the Crown; with the Medical Directors-General of the Army aud Navy.

3. Hore frequent sessions of the Council, or the appointment by it of an authorised permanent executive, or both; the few days at present given once in the year to its important and multifarious requirements being utterly inadequate to the attainment of any bepeficial results.

That your petitioners are strongly of opinion that the appointment of one examining board for the three kingdoms is the surest way to secure uniformity and efficieney of examination, and that the examiners should test praetically, as well as theoretically, the qualifications of all candidates for the licence to practise.

That your petitioners cordially approve of the recommendation by the Board of 'Trinity College, Dubliu, that after each State examination the names of the successful candidates and the numbers of their marks should be published, together with the names of the medical schools at which they had received their education, as is at present done by the Army and Navy Boards, and that no candidate should be admitted to examination until be had proved that he had received a regular medical education from some duly qualified body.

Finally, that your petitioners look upon it that, unless the third paragraph of Clause 22 of the proposed Medical Act be made imperative, and a prosecutor to be authorised by the cuuncil be appointed, it is almost certain to become a dead letter.

And your petitioners will ever pray.

signed on behalf of the Committee,

Joshda R. Hanvey, M.D., Chairman. Charles Aumstrong, M.D., Hon. Sec.

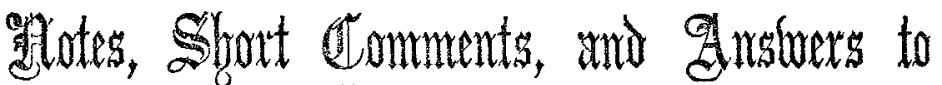 Correspontents.}

Sotth-Westery DISPENBART.

The Committee of this well-conducted charity have issued their first Report, which speaks more eloquently for its usefulness than any amount of special pleading. The district over which its bencfits are distributed is one of great and growing importance, while its selection of objects deserving of relief is so judicious as to make it co-operate rather than interfere with the local practitioners. Liberally as it is supported, and carefully as its funds are bestowed, its outlay was last year in excess of its income, so that the institution commences its second year with an adrerse balance of \&139, notwithstanding the services volunteered and performed by Drs. Beviss and Cunningham, and Messrs. Cass and Cooke. We hope the public will make a substantial acknowledgment of the claims so modestly set forth, but so signally well founded, of this useful charity.

Q.-We know of no regulation which forbids a Fellow of the College of Surgeons to dispense his own medicine, and to charge for it. But the practice of pretending to give advice gratis, and then charging an ordinary practitioner's fee for medicines supplied, is objectionable and undignified in a Fellow of the College.

"Gorng to the Dogs."

Ax odd change is taking place just now in a West-end establishment. A homoopathic chemist's shop is about to be converted into what is announced as "a canine infirmary." Is this a euphemism for "going to the dogs"?

2Ir. Thos. Davidson (Berwick-upon-Tweed) is thanked for his offer.

$$
\text { ThE ARM MEDICAL SERTICE. }
$$$$
\text { To the Editor of THB LANCET. }
$$

Sir,-Had jour correspondent, "Pro Bono Publico," read my letter more attentively, I think he would have discorered that the sentence be quotes was not penned unwittingly, but as a summary of the pith and marrow of the argument set forth by the advocates of the general staff system; and your correspondent's uncertainty in recognising anything very marked or
forcible in its character, I think tells rather in my farour, or that of the regimental sjstem versus the staff. I am sure, at least so far as the general opinion of medical officers is of ang ralue, it would speak for a continuance of the preserst state of things. I do not believe the proposed change is the offspriug of any vobler motise than economy, and to get as mueh hard work for the money as can possibly be screwed out of reduced establishments. As to sentiment, \&c., 5our correspondent mas disbeliere in it as much as he likes;
bat, nerertheless, it has been, and will be, a shield of defence to many a bat, nerertheless, it has been, and will be, a shield of defence to many
noble and worthy object. noble and worthy
July, 1870 .

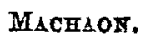

\section{WOXAY's Rights.}

Ax a performance which recently took place at the Roseangle Recreation Grounds, a female acrobat, called Fraulein Laura, had a very narrow escape, owing to one end of the supports giving way just as she had ascencled the high wire. She had the good luck, however, to fall between the ponderons shear poles, and escaped with noother injury than a terrible fricht to herself and "a sensation" to the audience. This female Blondin does not appear to go through her part alone, but a child ordinarily accompanies her on the wire. Such exhibitions as these seem to us both cruel and demoralising. If men think fit to incur these risks, the case is different where women and children are concerned. These are generally driven by poverty to undertake ansthing likely to pay, and they are at the mercy of their fathers, their husbands, or the proprietors of exhibitions. Why do not some of the strong-minded, energetic women, who are so loudly asserting the claims of their sex, seet to get these performinces interdicted? It is time for the law to step in for the protection of the children at any rate, and, indeed, the sooner exhibitions of female Blondins are prohibited the better.

Mr. G. E. Etheredge (Bromyard.)-The article must have miscarried.

\section{The Purification of Pre-breathed Atr.} To the Editor of The Laxcet.

SrR,-Four elements, carbon, hydrogen, oxygen, nitrogen, lie at the foundation of the human orcanism; form, as it were, its quaterniad of vitality. The atmosphere, as rich in the last two of these elements, is, physiologically, food-material, that is, from without destined to be assimilated within the body. As proof praetical of this, contrast many highly-fed but anæmic denizens of large towns with such as are, in the country, though sparsely fed, at the same time rosy, healthy, and well nourished; and credit the difference, in great part at least, to the nutrimental properties of air, care being, of course, first taken to select cases free from lung disease. Pathologically, phthisis is born of foul confined air, just as mueh as typhoid fever of bad water, or dyspepsia frequently of improper articles of diet. Emphatically it is the disease of bricks and mortar. On the double grounds, therefore, of physiology and pathology (sciences which, rightly interpreted, ever walk hand aud hand, and should be studied together, the former being the basis of the latter even more truly, if possible, than anatomy is of surgery), no question of hygiene can be more pressing than how constantly to provide a healthy in-dour atmosphere for respiratory and ot her purposes; and this particularly in large shops, workrooms and factories, churches, schools, and courts of judicature, theatres, assembly-rooms, and places of public resort generally, with last, yet certainly not least, dormitories; for, as in these most people of necessity continuously pass more time than in any other apartment, and as, further, during sleep the restorative processes are most active, and the susceptibility to morblfic infuence is at its maximum, here, above all, is it important that the external surroundings should be favour-
able. How far they ordinarily are so, let anyone (a medical man going to a able. How far they ordinarily are so, let anyone (a medical man going to a entering even a spacious bedroom occupied by a single individual. As for
the remedy of keeving the window slightly open all night, not to mention the remedy of keeping the window slightly open all night, not to mention the disturbing influence of traffic, \&c., in a climate like our own it is during a considerable part of the year innpplicable in the case of the delicate-
those, that is to say, who most stand in need of it. To resume, those, that is to say, who most stand in need of it. To resume, however.
There are two conceivable methods of ensuring a healthy in-door air. First, There are two conceivable methods of ensuring a healthy in-door air. First,
that of its constant renewal by processes of ventilation-a problem beset that of its constant renewal by processes of ventilation-a problem beset
with great practical difficulties as yet certainly far from being fully overcome. with great practical difficulties as yet certainly far from being fully overcome. Why then should we not conjoin with this (acting in the line of supplement,
not of course of substitution) the second possible mode of meeting the case not of course of substitution) the second possible mode of meeting the case - call ehemistry to the reseue, and endeavour to purify the air already
breathed, as well as get all the fresh supply we can? The work to be done would here be twofold. First, the removal of the injurious carbonic acid expired; secondly, the supply of fresh oxygen for that consumed in inspiration. The former purpose could be secured most easily, and at an expense
merely nominal, by the simple expedient of having a number of small tanks merely nominal, by the simple expedient of having a number of small tanks or vessels filled with lime-water scattered about the room, with a due supply
of fresh lime at the bottom for the water to redissolve, in place of that preof fresh lime at the bottom for the water to redissolve, in place of that preair. If any forms of animal or vegetable life could be tound to thrive in these hycienic aquaria, thus combining beauty with utility, so moch the these hygienic aquaria, thus combining beauty with utility, so much the
better. The necessity for a fresh supply of lime at the bottom would, of better. The necessity for a fresh supply of lime at the bottom would, of when breathed into. Next for the supply of fresh oxygen. In this ease we want a compound at once rich in that element, and yet easily parting from it, the medium of decomposition being, if possible, the simple one of the it, the medium of decomposition being, if possible, the simple one of the animal heat evolved in respiration. Have we not such a compound in permanganate of potash, and would it be too expensive for the purpose? The only thing to guard agaiust is not surcharging the air with an excess of a seif-registering apparatus for constant quantitative analysis of the amount of oxygen in the air, supplementing this amount when deficient in the way above named

In conclusion, $I$ would commend these thoughts to the consideration of practical chemists and physicians. Should I, however, have overlooked any previous suggestions in the same direction from any other quarter, it may, perhaps, be excused by the incessant claims of arduous country practice-
claims which clip the wings of wide re-earch, -and this contribution be claims which clip the wings of wide re earch, -and this contribution be subject, and a sumulus to the renewed exertions of those best able to cope

practically with its difficulties.
Dunster, Somersetshire, June, 1870.

Dr. J. Northeote Vinen must use his own discretion about continuing to forward the document he alludes to. We certainly cannot pledge ourselres to publish it. All communications to Thв LAxсET must rest. entirely on their own merits as regards their chances of being noticed.

$£$ need not be alarmed. The Lords do not oppuse a money Bill. The Bill is therefore safe.

Mr. J.A, Fizher.-No. The qualification is a surgical one only. 